\title{
Sickness absence and disability pension among women with breast cancer: a population-based cohort study from Sweden
}

Pia K. Kvillemo ${ }^{1}$, Lingjing Chen ${ }^{1 *}$ (D) Matteo Bottai ${ }^{2}$, Paolo Frumento ${ }^{2,3}$, Gino Almondo ${ }^{1}$, Ellenor Mittendorfer-Rutz ${ }^{1}$, Emilie Friberg ${ }^{1}$ and Kristina A. E. Alexanderson ${ }^{1}$

\begin{abstract}
Background: Women's return to work after diagnosis of breast cancer (BC) is becoming more prevalent. However, register-based national investigation on sickness absence (SA) and disability pension (DP) in BC women is lacking. The aim of the study was to explore SA and DP before and after a first BC diagnosis and the possibility to predict new cancer-related SA by using disease-related and sociodemographic factors.
\end{abstract}

Methods: A longitudinal register study of the 3536 women in Sweden aged 19-64 with a first BC diagnosis in 2010 was conducted by linkage of five nationwide registers. Particularly, detailed information on SA and DP was obtained from the National Social Insurance Agency. Descriptive statistics on SA and DP 2 years before through 3 years after the BC diagnosis were performed. The risk of having a new SA spell due to BC or BC-related diagnoses was modeled using logistic regression.

Results: The proportion of women with SA increased during the year following the BC diagnosis date and declined over the next 2 years to proportions before diagnosis. At the time of BC diagnosis, half of the women began a new SA spell $>14$ days with cancer, cancer-related, or mental diagnosis. Disease-related and sociodemographic factors including occupational sector, living area, age, cancer stage, educational level, and number of previous SA days showed statistical significance $(p<0.05)$ in predicting a new SA around BC diagnosis. By using these factors, it was possible to correctly predict $67 \%$ of the new SA spell.

Conclusions: SA among women with BC was elevated mainly in the first year after diagnosis. New SA following BC diagnosis can accurately be predicted.

Keywords: Sick leave, Breast cancer, Diagnosis specific, Cohort-study, Predictive model, Real-world data, Insurance medicine

* Correspondence: lingjing.chen@ki.se

'Division of Insurance Medicine, Department of Clinical Neuroscience, Karolinska Institutet, SE-171 77 Stockholm, Sweden

Full list of author information is available at the end of the article

C C The Author(s). 2021 Open Access This article is licensed under a Creative Commons Attribution 4.0 International License, which permits use, sharing, adaptation, distribution and reproduction in any medium or format, as long as you give appropriate credit to the original author(s) and the source, provide a link to the Creative Commons licence, and indicate if changes were made. The images or other third party material in this article are included in the article's Creative Commons licence, unless indicated otherwise in a credit line to the material. If material is not included in the article's Creative Commons licence and your intended use is not permitted by statutory regulation or exceeds the permitted use, you will need to obtain permission directly from the copyright holder. To view a copy of this licence, visit http://creativecommons.org/licenses/by/4.0/ The Creative Commons Public Domain Dedication waiver (http://creativecommons.org/publicdomain/zero/1.0/) applies to the data made available in this article, unless otherwise stated in a credit line to the data. 


\section{Introduction}

Breast cancer $(\mathrm{BC})$ is a major health problem with 1.67 million new cases worldwide annually [1]. Due to early detection and better treatments, mortality has decreased, hence more knowledge is needed on potential adverse long-term social consequences of $\mathrm{BC}$ for the growing number of survivors [2-4]. About half of the women diagnosed with $\mathrm{BC}$ are of working age, $[5,6]$ thus, $\mathrm{BC}$ might imply sickness absence (SA) or even disability pension (DP) for many of them due to effects of $\mathrm{BC}$ and/or BC treatments. Studies indicate that many women with $\mathrm{BC}$ value paid work highly and want to continue working after diagnosis or return to work (RTW) as soon as possible [7-10], and more knowledge is needed on patterns of SA and DP in order to get the knowledge base for interventions to facilitate part- or full-time (return to) work.

Studies of SA, DP, and RTW among women with BC indicate that the majority of RTW happens within 2 years $[5,11,12]$. Nevertheless, studies from Sweden and the Netherlands show that $\mathrm{BC}$ is associated with higher SA as long as 5 years after diagnosis [13-15] and that some are granted DP up to 10 years after diagnosis $[13,15,16]$. Advanced cancer stage, [11-13, 17] chemotherapy, [15, 18] pre-diagnosis SA, [13-15, 19] comorbidity, [20] and several sociodemographic factors [12-15, 17, 19-30] were negatively associated with RTW, alternatively positively with SA/DP, depending on the outcome used. Thus, such variables need to be included in this type of studies. However, studies of SA, DP, and RTW vary greatly in terms of study design, outcomes, selection of included women, national health insurance systems, and female employment frequency, $[5,11,16$, 20-22, 31-33] the latter implying different healthselection effects on outcomes. Sweden has a high female employment rate, also in higher ages (> 50 years old) [34]. Thus, the healthy-selection effects on outcomes in Sweden are smaller which is an advantage when aiming at gaining knowledge on associations of BC with future SA/DP.

Most of the previous studies were based on short follow-ups, selected study populations, high drop-out, or only self-reported SA/DP, and lacked information on DP and pre-diagnosis SA/DP [20]. Although elevated levels of post-diagnostic anxiety and depression have been reported, [35, 36] detailed analyses of SA and DP due to mental diagnoses have seldom been conducted. Thus, knowledge is limited on pre- and post-diagnosis diagnosis-specific SA and DP in women with BC, in nationwide population-based studies; knowledge that is needed to better understand the situation for women diagnosed with $\mathrm{BC}$, as a basis to identify potential risk factors for SA/DP as a basis for preventive measures. Moreover, in healthcare, among employers, insurance organizations, and patients, information regarding possible future SA following a BC diagnosis is asked for in order to take prevention measures and facilitate work accommodations [37]. Using information on disease-related and sociodemographic factors is one way to gain more such basic knowledge [38]. To the best of our knowledge, this is the first study to test a model for prediction of SA following a first $\mathrm{BC}$ diagnosis.

The aims were: (a) to explore the annual prevalence of SA and DP due to cancer, other somatic, and/or mental diagnoses during the 2 years before and the 3 years following a $\mathrm{BC}$ diagnosis, and (b) to predict risk of a new SA spell following a $\mathrm{BC}$ diagnosis.

\section{Methods}

A population-based longitudinal cohort study was performed.

We included all the 3536 women in Sweden, aged 1964 who were diagnosed with a first malignant neoplasm of breast (International Classification of Diseases 10th version (ICD-10) [39] code: C50) in 2010. Data were obtained from five nationwide registers as follows:

- The Board of Health and Welfare's: Cancer Register (all BC cases 1958-2010, diagnosis date, type, T, N, and M classifications [40]), Patient Register (main diagnosis, dates of in- and specialized outpatient care 2008-2010), and Cause of Death Register (dates 2010-2013); - Statistics Sweden's Longitudinal Integration Database for Health Insurance and Labor Market Studies (LISA) (age, educational level, marital status, family composition, birth country, occupational sector, geographical and type of living area in December 2009, emigration 2010-2012, not living in Sweden 2008 or 2009);

- National Social Insurance Agency's Micro-data for Analyses of Social Insurance (MiDAS) (SA and DP benefits 2008-2013: dates, full- or part-time, main diagnosis).Data were linked at individual level using the ten-digit personal identity numbers assigned to all residents in Sweden [41].

\section{SA and DP public benefit schemes in Sweden}

All people in Sweden $\geq 16$ years, with an income from work or unemployment benefits, with reduced work capacity due to disease or injury can be granted SA benefit from the Social Insurance Agency [42]. The employers usually provide reimbursement for the first 14 days of a SA spell, which is why we do not have information on SA spells $\leq 14$ days. From day 8 , a medical certificate issued by the treating physician is required. SA spells can go on for long periods, even years. All residents aged 19-64, irrespective of labour market status, can be granted DP if having long-term or permanent work incapacity due to disease or injury. People aged 19-29 can be granted temporary DP. In those ages DP can also be granted if, due to disease or injury, needing more 
time to complete elementary or secondary school. SA and DP can be granted for full-time $(100 \%)$ or part-time $(25,50$, or $75 \%)$ of ordinary working hours, that is, people can be on partial SA and DP at the same time. SA benefits cover $80 \%$ and DP $64 \%$ of lost income, up to a certain level.

\section{Measures}

We investigated two types of outcomes; DP and SA (for spells $>14$ days). SA and DP days were transformed into net days; e.g., 2 days on half-time SA or DP were counted as one net day. SA and DP diagnoses were coded by the certifying physician who assessed the patient's condition and work capacity. Diagnoses were for some of the analyses classified into four categories: 1): BC (ICD-10: C50), BC-related diagnoses (Z80, Z85, N61-N63), and other cancer (C00-D48), 2): mental diagnoses (F00-F99, Z73), 3): other diagnoses (all remaining ICD codes), and 4): missing information. The outcome in the predictive model was defined as starting a new SA spell $>14$ days due to one of the following SA diagnoses (C00-D48, Z80, Z85, N61-N63, F00-F99, or Z73) during the time-window of 14 days before to 29 days after the $\mathrm{BC}$ diagnosis. This time window was based on the frequencies of start of new SA spells in the full cohort, in relation to diagnosis date $\left(\mathrm{T}_{0}\right)$. For some women there was a delay before the diagnosis was included in the Cancer Register (even if the women were informed) and for others, treatment did not start until weeks later. The reason for including "diagnoses related to $\mathrm{BC}$ " and "other cancer diagnoses" in the predictive model was that sometimes a broader category of cancer diagnoses is given in the medical certificate [43]. Mental diagnoses were also included in the predictive model as a cancer diagnosis might lead to anxiety or depression [44, 45].

The included sociodemographic, disease-related, and comorbidity covariates (listed in Table 1) were selected for the predictive model based on previous findings regarding factors influencing SA and RTW $[13,14,17$, $20,23,25,26,29]$. Missing information on educational level was coded as elementary school. Cancer-stage groups were assigned using the TNM Classification of Malignant Tumours [40] and categorized as: TONOMO + stage $0+\mathrm{I}$, stage II, stage III + IV, and missing all TNM (with no $\mathrm{T}, \mathrm{N}$, or $\mathrm{M}$ information), respectively. When $\mathrm{T}$, $\mathrm{N}$, or $\mathrm{M}$ information was missing in one or two of the categories or classified as ' $\mathrm{X}$ ' (assessment not possible), the value was set to 0 . If more than one tumour was registered, with different diagnosis dates in 2010, the most advanced tumour was selected. The main ICD-10 diagnoses for healthcare were coded by the treating physicians. Healthcare due to uncomplicated delivery (O80) or not related to morbidity (e.g., screening) was excluded.

\section{Statistical analyses}

Different measures of SA and DP days were calculated.

In the in the period $730-15$ days before the $\mathrm{BC}$ diagnosis date $\left(\mathrm{T}_{0}\right)$ : having had $0,>0-90$, or $>90$ net SA days, having had 0, 0.25-365, or > 365 DP net days/year.

Per year, using the $\mathrm{BC}$ diagnosis date $\left(\mathrm{T}_{0}\right)$ as reference: having had $0,>0-30,>30-90,>90-180$, or $>180 \mathrm{SA}$ net days; in general, and by three SA diagnoses groups; having had any DP days/year, in general and by three DP diagnoses groups.

Moreover, the mean number of SA and of DP net days/year, respectively, were calculated for all women, using the $\mathrm{BC}$ diagnosis date $\left(\mathrm{T}_{0}\right)$ as reference, for the 2 years before $T_{0}$ and 3 years after $T_{0}\left(Y_{-2}\right.$ to $\left.Y_{+3}\right)$. This was done for all SA and DP as well as for the four SA/ DP diagnostic categories mentioned above. The annual numbers and proportions of women with SA/DP due to the different diagnoses were also calculated. The denominator used in these calculations varied somewhat over the years due to the exclusion of women (due to turning 65 years, emigration, or death).

In the predictive model regarding risk of new SA related to time of diagnosis, 2954 women were included. For those analyses we excluded the 521 women (14.7\%) already on SA or on DP for full-time or nearly full-time (75-100\%) at $\mathrm{T}_{0}$. Additionally, 61 women were excluded due to lack of covariate information, or because of extreme values on some of the continuous variables, e.g., number of healthcare visits or inpatient days.

The risk of a new SA spell due to BC or related diagnoses, other cancer diagnoses, or mental diagnoses was modelled using multivariable logistic regression [46, 47] with a logistic model formulated as follows: log $\left[\mathrm{P}\left(\mathrm{Y}_{\mathrm{i}}=1\right) / \mathrm{P}\left(\mathrm{Y}_{\mathrm{i}}=0\right)\right]=\mathrm{x}_{\mathrm{i}}{ }^{\prime} \beta$ where $\mathrm{Y}_{\mathrm{i}}$ denotes the SA status of individual $i$, and $\mathrm{x}_{\mathrm{i}}$ is a vector of observed covariates. Natural cubic splines [48-50] were used to model potentially nonlinear effects of continuous covariates. We used two internal knots at the empirical quantiles $1 / 3$ and $2 / 3$. The five variables that were modelled using splines were: age and number of previous: SA days, DP days, outpatient healthcare visits, and inpatient days, respectively, in the two pre-diagnostic years. We developed two versions of the model: one without interactions; and another one with interactions between family composition-marital status, region-city size, previous SA days-outpatient visits, previous SA days-inpatient days. An optimal threshold $c$ was selected, such that predicting $S A$ whenever the fitted probability was above $c$, minimized the sum of false positive (FP) and false negative (FN) and maximized the proportion of correctly classified observations. Also, the receiver operating characteristic (ROC) was calculated. These values were also calculated using leave-one-out cross-validations. 
Table 1 Characteristics of the study cohort and the sub-cohort for modelling

\begin{tabular}{|c|c|c|c|c|}
\hline \multirow[t]{2}{*}{ Covariates } & \multicolumn{2}{|c|}{ The whole cohort } & \multicolumn{2}{|c|}{ The cohort used for modelling ${ }^{c}$} \\
\hline & Number & (\%) & Number & (\%) \\
\hline All & 3536 & 100 & 2954 & 100 \\
\hline \multicolumn{5}{|l|}{ Age group } \\
\hline $18-35$ & 122 & 3.5 & 111 & 3.8 \\
\hline $36-45$ & 665 & 18.8 & 610 & 20.7 \\
\hline $46-50$ & 583 & 16.5 & 515 & 17.4 \\
\hline $51-55$ & 630 & 17.8 & 525 & 17.8 \\
\hline $56-60$ & 844 & 23.9 & 664 & 22.5 \\
\hline $61-63$ & 692 & 19.6 & 529 & 17.9 \\
\hline \multicolumn{5}{|l|}{ Country of birth } \\
\hline Sweden & 2950 & 83.4 & 2509 & 84.9 \\
\hline Other country & 586 & 16.6 & 445 & 15.1 \\
\hline \multicolumn{5}{|l|}{ Educational level } \\
\hline Elementary school ( $\leq 9$ years) & 551 & 15.6 & 378 & 12.8 \\
\hline High school (10-12) & 1549 & 43.8 & 1265 & 42.8 \\
\hline College/University (> 12) & 1436 & 40.6 & 1311 & 44.4 \\
\hline \multicolumn{5}{|l|}{ Geographic living area } \\
\hline North & 425 & 12.0 & 344 & 11.7 \\
\hline Middle & 486 & 13.7 & 403 & 13.6 \\
\hline Stockholm & 823 & 23.3 & 710 & 24.0 \\
\hline West & 934 & 26.4 & 767 & 26.0 \\
\hline South & 868 & 24.6 & 730 & 24.7 \\
\hline \multicolumn{5}{|l|}{ Type of living area } \\
\hline Larger cities & 1376 & 38.9 & 1172 & 39.7 \\
\hline Medium cities & 1252 & 35.4 & 1051 & 35.6 \\
\hline More rural areas & 908 & 25.7 & 731 & 24.8 \\
\hline \multicolumn{5}{|l|}{ Family composition } \\
\hline Married/cohab., no child at home & 1042 & 29.5 & 852 & 28.8 \\
\hline Married/cohab., child at home & 1235 & 34.9 & 1129 & 38.2 \\
\hline Single, no child at home & 885 & 25.0 & 656 & 22.2 \\
\hline Single, child at home & 374 & 10.6 & 317 & 10.7 \\
\hline \multicolumn{5}{|l|}{ Marital status } \\
\hline Unmarried, divorced, widow & 1523 & 43.1 & 1228 & 41.6 \\
\hline Married, registered partnership & 2013 & 56.9 & 1726 & 58.4 \\
\hline \multicolumn{5}{|l|}{ Occupational sector } \\
\hline Not in paid work/no information & 810 & 22.9 & 379 & 12.8 \\
\hline Public & 1409 & 39.9 & 1330 & 45.0 \\
\hline Private & 1317 & 37.3 & 1245 & 42.2 \\
\hline \multicolumn{5}{|l|}{ Cancer stage } \\
\hline Missing all T, N, M & 25 & 0.7 & & \\
\hline TONOMO + Stage $0+1$ & 2120 & 60.0 & 1799 & 60.9 \\
\hline Stage II & 1162 & 32.9 & 990 & 33.5 \\
\hline Stage III + IV & 229 & 6.5 & 165 & 5.6 \\
\hline
\end{tabular}


Table 1 Characteristics of the study cohort and the sub-cohort for modelling (Continued)

\begin{tabular}{|c|c|c|c|c|}
\hline \multirow[t]{2}{*}{ Covariates } & \multicolumn{2}{|c|}{ The whole cohort } & \multicolumn{2}{|c|}{ The cohort used for modellingc } \\
\hline & Number & $(\%)$ & Number & (\%) \\
\hline \multicolumn{5}{|l|}{ Previous SA, net days $s^{a, b}$} \\
\hline No previous SA & 2870 & 81.2 & 2444 & 82.7 \\
\hline $0.25-90$ & 485 & 13.7 & 417 & 14.1 \\
\hline$\geq 90$ & 181 & 5.1 & 93 & 3.2 \\
\hline \multicolumn{5}{|c|}{ Previous SA, diagnoses ${ }^{a}$} \\
\hline Mental diagnoses & 161 & 4.6 & 124 & 4.2 \\
\hline Other diagnoses & 540 & 15.3 & 412 & 14.0 \\
\hline \multicolumn{5}{|l|}{ Previous DP net days ${ }^{a}$} \\
\hline 0 & 2908 & 82.2 & 2771 & 93.8 \\
\hline $0,25-365$ & 180 & 5.1 & 153 & 5.2 \\
\hline$\geq 365$ & 448 & 12.7 & 30 & 1.0 \\
\hline \multicolumn{5}{|c|}{ Previous DP diagnoses $^{a}$} \\
\hline Mental diagnoses & 181 & 5.1 & 47 & 1.6 \\
\hline Other diagnoses & 466 & 13.2 & 137 & 4.6 \\
\hline \multicolumn{5}{|c|}{ Previous visits in specialized outpatient care ${ }^{a}$} \\
\hline 0 & 1549 & 43.8 & 1390 & 47.1 \\
\hline $1-2$ visits & 1039 & 29.4 & 898 & 30.4 \\
\hline$\geq 3$ visits & 948 & 26.8 & 666 & 22.6 \\
\hline \multicolumn{5}{|c|}{ Previous visits in outpatient care, diagnoses ${ }^{a}$} \\
\hline Mental diagnoses & 166 & 4.7 & 72 & 2.4 \\
\hline Other diagnoses & 1825 & 51.6 & 1441 & 48.8 \\
\hline \multicolumn{5}{|c|}{ Previous inpatient care, days ${ }^{a}$} \\
\hline 0 & 3123 & 88.3 & 2709 & 91.7 \\
\hline $1-14$ days & 354 & 10.0 & 235 & 8.0 \\
\hline$\geq 14$ days & 59 & 1.7 & 10 & 0.3 \\
\hline \multicolumn{5}{|c|}{ Previous inpatient care, diagnoses ${ }^{\mathrm{a}}$} \\
\hline Mental diagnoses & 32 & 0.9 & 11 & 0.4 \\
\hline Other diagnoses & 391 & 11.1 & 238 & 8.1 \\
\hline
\end{tabular}

The table included sociodemographic factors, cancer stage, and previous sickness absence (SA), disability pension (DP), and healthcare ( $\mathrm{n}$ and \%) for the cohort of all women in Sweden $<65$ years with a first breast cancer diagnosis in 2010 as well as for those included in the logistic regression used to build a predictive model

${ }^{a}$ Previous $=$ in the period $730-15$ days before the $B C$ diagnosis date

${ }^{b}$ The first 14 days of SA spells are not included

c That is, those at risk for a new SA spell

\section{Results}

Sociodemographic and diagnostic covariates are presented in Table 1 for the entire cohort $(N=3536)$ as well as for the group included in the modelling $(n=2954)$. About $40 \%$ of the women in both groups were $\geq 56$ years. The compositions of women regarding distribution of characteristics in the two groups were fairly similar, except for percentage of women with no DP during the two pre-diagnostic years: $82 \%$ among all vs. $94 \%$ in the model, as expected due to the inclusion criteria in the modelling group. The majority had the earliest stages of BC. In the two pre-diagnosis years $\left(\mathrm{Y}_{-1}\right.$ and $\left.\mathrm{Y}_{-2}\right)$, the majority had no SA days ( $81 \%$ vs. $83 \%)$, about half $(56 \%$ vs. 53\%) had at least one visit in specialized outpatient healthcare while few $(12 \%$ vs. $8 \%)$ had at least one inpatient day. At BC diagnosis, $11.3 \%$ of the women were already on SA and $17.5 \%$ already on DP.

\section{Proportions of women with SA and/or DP}

During the year after the $\mathrm{BC}$ diagnosis date $\left(\mathrm{Y}_{+1}\right), 28 \%$ of the women had no SA > 14 days (Table 2), while 67\% had SA due to cancer; nearly half of those (32\%) for > 180 days. In the second year $\left(Y_{+2}\right), 35 \%$ of the women had at least some SA, regardless of SA diagnosis. For cancer SA diagnoses, the corresponding proportion was $25 \%$ during $Y_{+2}$. During $Y_{+3}$, the corresponding proportions 
Table 2 Number and percentages of women having different categories of number of sickness absence (SA) or disability pension (DP) net days per year, for the five studied years

\begin{tabular}{|c|c|c|c|c|c|c|}
\hline SA/DP/ diagnoses & $\begin{array}{l}\text { Categories of number } \\
\text { of SA/DP days/year }\end{array}$ & $\begin{array}{l}Y_{-2} \\
n(\%)\end{array}$ & $\begin{array}{l}Y_{-1} \\
n(\%)\end{array}$ & $\begin{array}{l}Y_{+1} \\
n(\%)\end{array}$ & $\begin{array}{l}Y_{+2} \\
n(\%)\end{array}$ & $\begin{array}{l}Y_{+3} \\
n(\%)\end{array}$ \\
\hline & & $3522(100)$ & $3534(100)$ & $3536(100)$ & $3492(100)$ & $3191(100)$ \\
\hline \multicolumn{7}{|l|}{$S A^{a}$} \\
\hline \multirow[t]{5}{*}{ All } & 0 & 3115 (88.4) & 3134 (88.7) & $978(27.7)$ & $2282(65.3)$ & $2401(75.2)$ \\
\hline & $>0-30$ & $198(5.6)$ & $206(5.8)$ & $485(13.7)$ & $422(12.1)$ & $324(10.2)$ \\
\hline & $>30-90$ & $98(2.8)$ & $105(3.0)$ & $440(12.4)$ & $297(8.5)$ & $165(5.2)$ \\
\hline & $>90-180$ & $55(1.6)$ & $50(1.4)$ & $366(10.4)$ & $213(6.1)$ & $133(4.2)$ \\
\hline & $>180$ & $56(1.6)$ & $39(1.1)$ & 1267 (35.8) & $278(8.0)$ & $168(5.3)$ \\
\hline \multirow[t]{5}{*}{ Cancer $^{\mathrm{b}}$} & 0 & 3509 (99.6) & 3506 (99.2) & 1165 (32.9) & $2610(74.7)$ & $2801(87.8)$ \\
\hline & $>0-30$ & $\leq 8$ & $19(0.5)$ & $486(13.7)$ & $306(8.8)$ & $124(3.9)$ \\
\hline & $>30-90$ & $\leq 8$ & $\leq 8$ & $408(11.5)$ & $224(6.4)$ & $89(2.8)$ \\
\hline & $>90-180$ & $\leq 8$ & $\leq 8$ & $337(9.5)$ & $151(4.3)$ & $75(2.4)$ \\
\hline & $>180$ & $\leq 8$ & $\leq 8$ & $1140(32.2)$ & $201(5.8)$ & $102(3.2)$ \\
\hline \multirow[t]{5}{*}{ Mental $^{c}$} & 0 & $3423(97.2)$ & $3435(97.2)$ & $3430(97.0)$ & $3354(96.0)$ & $3074(96.3)$ \\
\hline & $>0-30$ & $42(1.2)$ & $48(1.4)$ & $25(0.7)$ & $44(1.3)$ & $50(1.6)$ \\
\hline & $>30-90$ & $22(0.6)$ & $30(0.8)$ & $22(0.6)$ & $43(1.2)$ & $21(0.7)$ \\
\hline & $>90-180$ & $16(0.5)$ & $11(0.3)$ & $15(0.4)$ & $19(0.5)$ & $21(0.7)$ \\
\hline & $>180$ & $19(0.5)$ & $10(0.3)$ & $44(1.2)$ & $32(0.9)$ & $25(0.8)$ \\
\hline \multirow[t]{5}{*}{ Other $^{d}$} & 0 & 3219 (91.4) & 3246 (91.9) & 3331 (94.2) & 3208 (91.9) & $2848(89.3)$ \\
\hline & $>0-30$ & $158(4.5)$ & $153(4.3)$ & $85(2.4)$ & $151(4.3)$ & $205(6.4)$ \\
\hline & > 30-90 & $74(2.1)$ & $73(2.1)$ & $29(0.8)$ & $62(1.8)$ & $63(2.0)$ \\
\hline & $>90-180$ & $37(1.1)$ & $36(1.0)$ & $16(0.5)$ & $30(0.9)$ & $35(1.1)$ \\
\hline & $>180$ & $34(1.0)$ & $26(0.7)$ & $75(2.1)$ & $41(1.2)$ & $40(1.3)$ \\
\hline \multicolumn{7}{|l|}{ DP } \\
\hline All & $>0$ & $613(17.4)$ & $619(17.5)$ & $606(17.1)$ & $553(15.8)$ & $492(15.4)$ \\
\hline Cancer & $>0$ & $\leq 8$ & $\leq 8$ & $12(0.3)$ & $13(0.4)$ & $21(0.7)$ \\
\hline Mental & $>0$ & $171(4.9)$ & $170(4.8)$ & $160(4.5)$ & $148(4.2)$ & $135(4.2)$ \\
\hline Other ${ }^{b}$ & $>0$ & $445(12.6)$ & $449(12.7)$ & $436(12.3)$ & $393(11.3)$ & $338(10.6)$ \\
\hline No SA/DP & 0 & $2578(73.2)$ & $2579(73.0)$ & $543(15.4)$ & 1812 (51.9) & $1990(62.4)$ \\
\hline Not included ${ }^{e}$ & & 14 & $\leq 8$ & 0 & 44 & 345 \\
\hline \multicolumn{7}{|c|}{ Reasons for not being included the specific year } \\
\hline \multicolumn{2}{|l|}{$>65$ years of age } & & & & & 248 \\
\hline \multicolumn{2}{|c|}{ Death $\leq 65$ year of age } & & & & 43 & 91 \\
\hline \multicolumn{2}{|c|}{ Not living in Sweden and $\leq 65$ years } & 14 & $\leq 8$ & & $\leq 8$ & $\leq 8$ \\
\hline
\end{tabular}

Included in the table were all women in Sweden $<65$ years with a first breast cancer diagnosis in $2010(N=3536)$, during the 2 years before and 3 years after the breast cancer diagnosis date, presented for all SA/DP as well as by three categories of SA/DP diagnoses. Also, the number of women not included in the respective year are presented by reason for not being included

${ }^{a}$ The first 14 days of SA spells are excluded

b ICD-codes: C00-D48, Z80, Z85, N61-N63

c ICD-codes: F00-F99, Z73

"In the group" Other diagnoses", also SA/DP with missing information on diagnosis were included

e Women who turned 65, died, or emigrated were included up to and including the year of the event

were 25 and 12\%, respectively. The proportions with SA due to mental diagnoses did not vary much between the studied years $(3-4 \%)$. For SA due to other and missing diagnoses, the corresponding proportions were $8-11 \%$ all years, except for $Y_{+1}$ when it was $6 \%$. The proportion of women with DP ranged from 15 to $18 \%$ during all the five studied years. During $Y_{+1}, 15 \%$ of the women had neither SA nor DP. Before $\mathrm{BC}$ diagnosis, i.e., during $\mathrm{Y}_{-2}$ and $\mathrm{Y}_{-1}$, that proportion was $73 \%$. During $\mathrm{Y}_{+2}$ and $\mathrm{Y}_{+3}$, the corresponding proportions were 52 and $62 \%$, respectively. 


\section{Mean SA and DP days/year}

During $Y_{+1}$, the mean number of SA days irrespective of SA diagnosis, among all the women in the cohort was 121.3. This was significantly higher than the numbers before diagnosis; (6.7 in $\mathrm{Y}_{-1}$ and 9.0 in $\mathrm{Y}_{-2}$ ) (Fig. 1). During $Y_{+1}, 108.8$ of these SA days were due to cancer. That number was lower already in $Y_{+2}$, i.e., 26.6 days. In $\mathrm{Y}_{+3}$, it was 14.0 days. Mean number of DP days/year was about 50 before $\mathrm{BC}$ diagnosis. Due to that some of the older women who already had DP in the year before $\mathrm{T}_{0}$ became 65 years of age, that number of DP days decreased to about 40 days/year in $Y_{+2}$ and $Y_{+3}$. Even in $Y_{+1}$, the mean numbers of SA/DP days for the whole cohort was below less than half of the year.

\section{New SA spell}

For the 3015 women who did not have an ongoing SA nor DP of the extent of $75-100 \%$ at the time of BC diagnoses $\left(\mathrm{T}_{0}\right)$, Table 3 shows the numbers and percentages of women who had a first new SA spell in relation to $T_{0}$. The same is shown for three specific SA diagnostic groups, i.e., cancer, mental diagnoses, and the other diagnoses (including missing), respectively. Of these women, $51 \%$ had a first new SA spell in relation to $\mathrm{T}_{0}$, that is, the period that was studied in the predictive modelling. Of these SA spells, 95\% were due to cancer. In the following 30-day period, i.e., from 30 to 59 days after $\mathrm{T}_{0}$, another $20 \%$ had a first SA spell, of which $96 \%$ were with cancer. In the period from $T_{0}$ until end of follow-up 3 years later, a little less than one fifth of the women $(18 \%)$ had no new SA spells. Nine women were granted DP during that period. That is, about $80 \%$ of those at risk of a new SA spell following BC diagnosis, had such a spell in the first year $\left(\mathrm{Y}_{+1}\right)$, and the majority of them (70\%) in the first 3 months.

\section{Predictive model}

The model without interactions had similar crossvalidated ROC-AUC as the model with interactions (results not shown). We, therefore, choose to report results for the simpler model without interactions for the sake of parsimony. Out of the variables (see Table 1) included in the multivariable logistic regression model for the risk of having a new SA spell $>14$ days (due to $\mathrm{BC}$ or related diagnoses, other cancer diagnoses, or mental diagnoses) in connection with a first $\mathrm{BC}$ diagnosis $\left(\mathrm{T}_{0}\right)$, the following variables were statistically significant $(p<0.05)$ : occupational sector, living area, age, cancer stage, educational level, and number of previous net SA days (listed according to predictive strength from high to low). In Fig. 2, the receiver operating characteristic (ROC) curve is illustrated. The dot indicates the coordinates (FP, FN) corresponding to the selected value of threshold $c$. The predictive model could correctly predict $35 \%$ out of 2954 women, given the optimal threshold 0.56. Results are summarized in Table 4 where the area under the curve (AUC) $[51,52]$ is also reported.

\section{Discussion}

In this longitudinal population-based cohort study of all women in Sweden aged 19-64 years with a first BC diagnosis in 2010, the proportion with SA > 14 days increased substantially in the post-diagnostic 12 months. Nevertheless, most women were not on SA for extensive

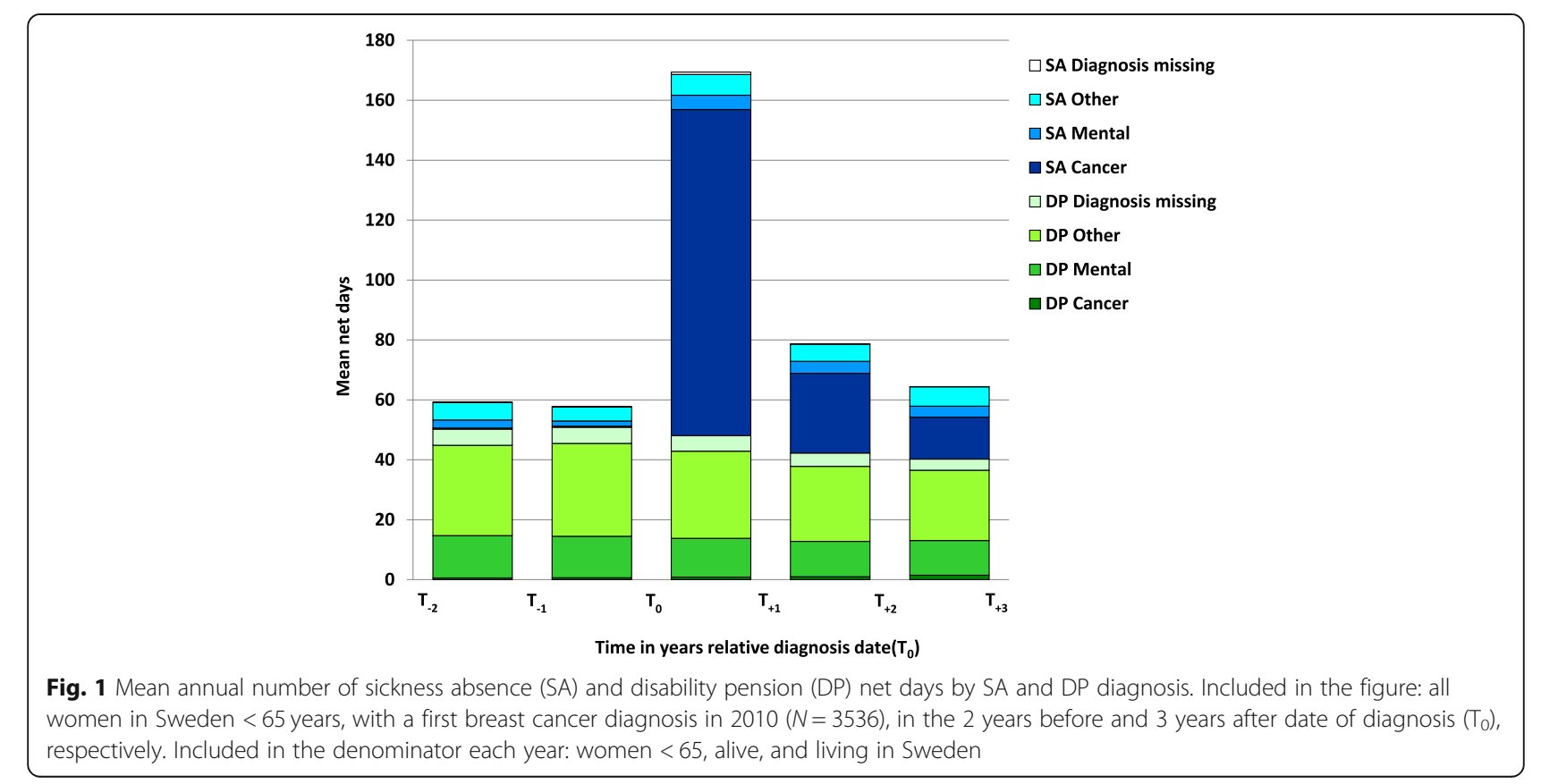


Table 3 Number and percentages of women with a new sickness absence (SA) spell (> 14 days)

\begin{tabular}{|c|c|c|c|c|}
\hline Days relative to $T_{0}$ & $\begin{array}{l}\text { Number (\% of all women, column } \\
\%)^{\mathrm{a}}\end{array}$ & $\begin{array}{l}\text { Cancer } \\
\text { (row\%) }\end{array}$ & $\begin{array}{l}\text { Mental } \\
\text { (row\%) }\end{array}$ & $\begin{array}{l}\text { Other diagnoses } \\
\text { (row\%) }\end{array}$ \\
\hline $\begin{array}{l}\text { No new SA spell before } T_{0} \text { to end of follow- } \\
\text { up }^{c_{1}}\end{array}$ & $536(17.8)$ & - & - & - \\
\hline 14 days before $T_{0}$ to 29 days after $T_{0}$ & $1535(50.9)$ & 95 & 3 & 2 \\
\hline 30-59 days after $T_{0}$ & 599 (19.9) & 96 & 1 & 3 \\
\hline $60-89$ days after $T_{0}$ & $152(5.0)$ & 93 & 3 & 4 \\
\hline 90-119 days after $T_{0}$ & $78(2.6)$ & 92 & 1 & 6 \\
\hline 120-179 days after $T_{0}$ & $48(1.6)$ & 90 & 0 & 10 \\
\hline 180-364 days after $T_{0}$ & $19(0.6)$ & 68 & 0 & 32 \\
\hline 365-729 days after $T_{0}$ & $21(0.7)$ & 57 & 14 & 29 \\
\hline$\geq 730$ days after $T_{0}$ & $27(0.9)$ & 18 & 15 & 67 \\
\hline
\end{tabular}

The included individuals were 3015 women $<65$ years related to date of a first breast cancer diagnosis in 2010 (T0), during the following 3 years; all SA and diagnosis-specific SA (cancer, mental, or others)

${ }^{a}$ Women already (nearly) full-time (75-100\%) SA or disability pension (DP) at $\mathrm{T}_{0}$ were not included

b ICD-codes: C00-D48, Z80, Z85, N61-N63

c Nine of these women were granted DP during follow-up

times during the first year after diagnosis date (e.g., > 180 net days) and about 17\% were already on SA/DP due to other diagnoses when diagnosed with $\mathrm{BC}$. In the third year after $\mathrm{BC}$ diagnosis date $\left(\mathrm{Y}_{+3}\right)$, the mean number of SA and DP days was low and $25 \%$ of the women had no SA at all. The variation in proportion of women with DP was minor during the 5 years being studied. The elevated proportion of women on SA and the higher number of SA days after $\mathrm{BC}$ diagnosis, compared to the years before $\mathrm{BC}$ diagnosis, was in SA due to cancer throughout follow-up, e.g., not due to mental diagnoses. Of the 3015 women not already on SA/DP at time of BC diagnosis, $51 \%$ had a new SA spell and for $98 \%$ of them the SA was due to a cancer diagnosis, cancer-related diagnosis, or mental diagnosis. Using a predictive model including disease-related and socio-demographic factors, $67 \%$ of the women could be correctly classified into having or not having a new SA spell, indicating that it

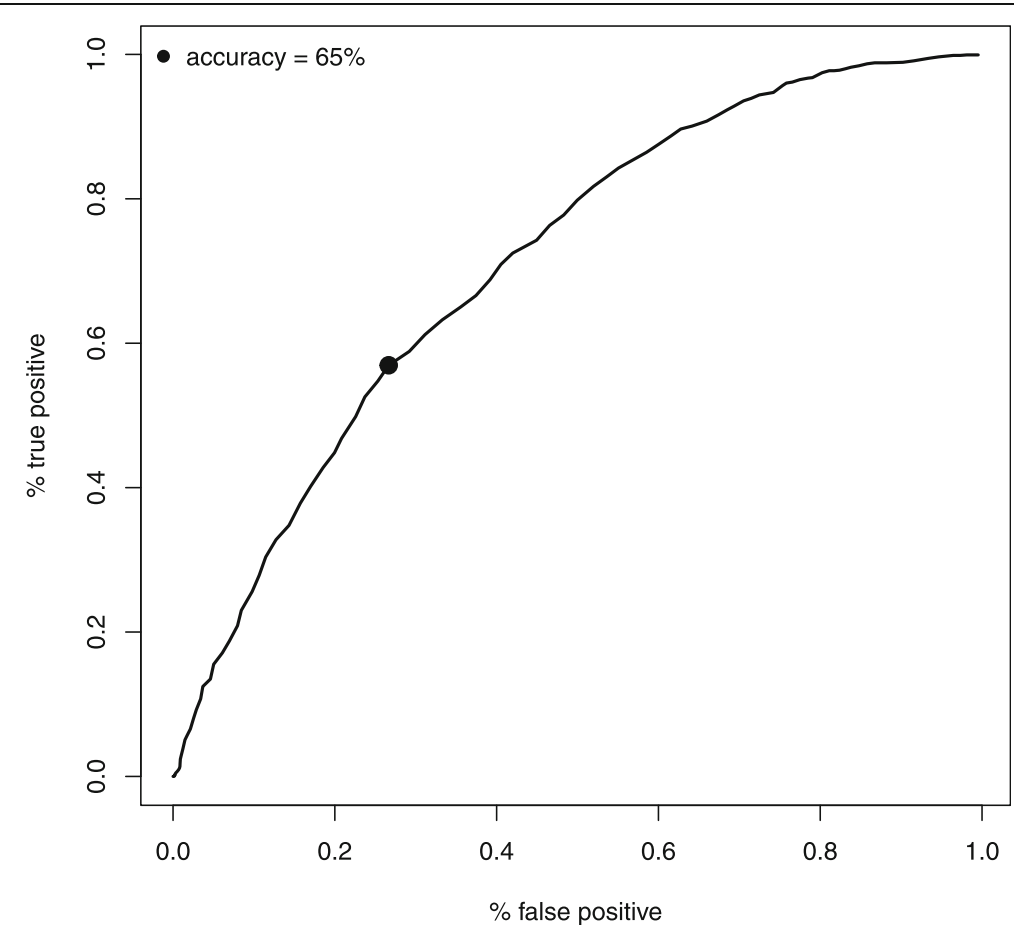

Fig. 2 The receiver operating characteristic (ROC) curve. Proportion of false positive/negative at different values of $c$ in the cohort of women in Sweden $<65$ years with a first breast cancer diagnosis in 2010. The dot corresponds to the optimal choice of threshold c 
Table 4 Performance measures of model without interactions, after leave-one-out cross-validations

\begin{tabular}{ll}
\hline & Values \\
\hline \% False positive & 13 \\
\% False negative & 21 \\
\% Correct & 35 \\
Sensitivity & 0.57 \\
Specificity & 0.73 \\
Area under the curve (AUC) & 0.71 \\
\hline
\end{tabular}

The values included in the table were: proportion of false positive (FP) and false negative ( $F N)$, proportion of correctly classified observations, and area under the curve (AUC) in the analyses of women in Sweden $<65$ years with a first breast cancer diagnosis in $2010(N=2954)$

1 Women not at risk of a new SA spell at date of breast cancer diagnosis were not included (that is, those already on (nearly) full-time SA or DP (75-100\%)

would be possible to predict risk of future SA among working-aged women diagnosed with $\mathrm{BC}$.

\section{Strengths and limitations}

The data from the entire population of Sweden provided us with a rare opportunity to study SA and DP in connection with $\mathrm{BC}$ diagnosis in all women of working age. Other strengths are the longitudinal cohort design, that all women fulfilling the inclusion criteria of a first $\mathrm{BC}$ diagnosis in a whole country could be included, not a sample; also that extensive microdata on morbidity and sociodemographic variables from several high-quality registers could be linked at individual level [41, 53, 54]; and that data were not self-reported, avoiding recall bias. The large cohort also allowed sub-group analyses of specific SA/DP diagnoses, not only the BC diagnosis. The latter circumstance makes the results and model more useful in practice. High female employment frequency, complete coverage of the public SA/DP insurances, and no dropouts make the internal validity of the study very strong. A further strength is that we were able to exclude women when they during follow-up, due to death, turning 65 , or emigration no longer were at risk of the outcome SA/DP. Findings can be generalized to women with $\mathrm{BC}$ in countries with comparable employment frequencies and coverage of SA/DP benefits. Another strength was the use of several different measures of SA and DP, which provided a wide picture of the complex data that SA and DP data provide, e.g., regarding skewed distribution, regarding occurrence of spells and durations of spells and time between spells, different diagnoses and seriousness [55-57].

Regarding the predictive model, we found that the specified interactions did not improve the predictive performance of the model. While it is possible that other interactions between included variables exists, we expect limited gains in terms of predictive power from the inclusion of more interactions, as well as a risk for overfitting. The aim here was to explore if predictions could be possible, which we found. Future studies need to further develop such analyses, both regarding this outcome and others, e.g., durations of SA spells.

The validity of SA and DP diagnoses is sometimes discussed but seldom investigated. To the best of our knowledge, there is only one such study, regarding SA diagnoses, [43] and that study found the validity to be acceptable. The validity of DP diagnoses is likely to be even higher, since DP is only granted after a long process of medical evaluation [42]. However, the stigma associated with mental diagnoses [58] might imply an underestimation of SA/DP due to such diagnoses. Other limitations of our study are that we had no information on SA spells $\leq 14$ days and only information about the first and main SA diagnosis of a SA spell. Further, we did not have information on cancer treatment, which is a factor that might attenuate the association between cancer stage and SA [14, 15]. Previous studies have, e.g., shown that chemotherapy is associated with higher levels of SA/DP $[15,18]$.

\section{Discussion of results}

We were able to replicate previous findings that the prevalence of SA was considerably higher in the year post-BC diagnosis than before diagnosis, using a population-based nationwide cohort $[13,14]$. In a previous Swedish population-based study of all women aged 20-65 with a first BC diagnosis in 2005, [13] almost the same proportion of women as here presented (71\% vs. $72 \%$ ) had some SA during the first 12 months following $\mathrm{BC}$ diagnosis. In the cohort from 2005, however, a larger proportion of women, i.e., 19\%, had SA already in the year before BC diagnosis, compared to $11 \%$ in our 2010 cohort. Also, proportions on DP were slightly higher in the pre-diagnostic year $\left(\mathrm{Y}_{-1}\right)$ in the 2005 cohort compared to the current cohort, $20.6 \%$ vs. $17.5 \%$. In the following 2 years, the decline in SA was somewhat faster in our 2010 cohort. This difference might imply an impact of the stricter Swedish SA/DP regulations implemented in 2008 [59, 60]. However, the hypothesis should be studied further using other study designs.

The higher prevalence of SA after BC diagnosis, compared to the pre-diagnostic period, was due to cancer only, not due to mental nor to other somatic diagnoses in neither our cohort nor the 2005 cohort used in the previous Swedish study from our group, [13] i.e., SA due to mental diagnoses did not increase after the $\mathrm{BC}$ diagnosis. This is noteworthy, as studies have reported higher risks of anxiety and depression after $\mathrm{BC}$ diagnosis $[35,36]$. One possible explanation is that mental disorders in women with $\mathrm{BC}$ are not recognized by sickness certifying physicians [61]. Another explanation is that such mental disorders did not reduce work capacity to 
such a high level that SA was required or that the women, if needed, soon had adequate treatment for mental disorders - more knowledge is needed on this. It is also possible that mental diagnoses was stated as a secondary SA diagnosis or becoming a main SA diagnosis later during the SA spell [62] and thus not captured by our data.

Regarding the predictive model, our ROC.AUC of 0.71 is considered below recommended levels for clinical use $[38,63]$. Nevertheless, the results from the model are promising regarding the possibility to further develop a predictive model. It also can be used to inform patients, healthcare staff, and other stakeholders that all women diagnosed with BC do not require SA very soon.

Our results highlight the importance of communicating to women with $\mathrm{BC}$ as well as to employers of the fact that most women with $\mathrm{BC}$ return to work rather quickly, in order to promote optimal work adjustments as soon as possible, especially for groups with an elevated risk of SA/DP.

\section{Conclusions}

In this population-based prospective cohort study we found that although $\mathrm{BC}$ and $\mathrm{BC}$ treatment can have large impacts on work capacity, not all women diagnosed with $\mathrm{BC}$ had extensive SA/DP even in the first 12 months after diagnosis. Moreover, it is possible to give a good prediction of which women with $\mathrm{BC}$ who are at high risk of new SA. Our predictive model should be further developed to assist the RTW measures for people with cancer diagnosis in the future.

\section{Abbreviations}

BC: Breast cancer; SA: Sickness absence; DP: Disability pension; RTW: Return to work; ICD-10: International Classification of Diseases 10th version; LISA: Longitudinal Integration Database for Health Insurance and Labor Market Studies; MiDAS: Micro-data for Analyses of Social Insurance; FP: False positive; FN: False negative; ROC: Receiver operating characteristic; AUC: Area under the curve

\section{Acknowledgements}

Not applicable.

\section{Data permission}

The data used in this study is administered by the Division of Insurance Medicine, Karolinska Institutet. These data cannot be made available publically due to privacy regulations. Specifically, according to the General Data Protection Regulation, the Swedish law SFS 2018:218, the Swedish Data Protection Act, the Swedish Ethical Review Act, and the Public Access to Information and Secrecy Act, these type of sensitive data can only be made available for specific purposes, including research that meets the criteria as determined by a legal review. The Ethical Review Board and the datakeeping authorities have made these sensitive personal microdata available for the project with the strict notion that only researchers of the project can work with them. Readers may contact Professor Kristina Alexanderson (kristina.alexanderson@ki.se) regarding the data administrated by the Division of Insurance Medicine, Karolinska Institutet, included analyses conducted for this study.

\section{Authors' contributions}

Contribution statement: KA, PK, EM-R, and EF were responsible for the study concept and design. KA obtained the research funding and the database. PF conducted the data management and analysis, aided by MB. GA conducted the reanalyses, e.g., regarding the prediction model, informed by PF and MB. PK outlined the first versions of the results and manuscript, thereafter, LC finalized the results and manuscript, and was responsible for manuscript submission. All authors (KA, PK, LC, EM-R, MB, PF, GA, and EF) were involved in result interpretation and manuscript revisions. All authors had full access to all of the data in the study and took responsibility for the integrity of the data and the accuracy of the data analysis. The authors read and approved the final manuscript.

\section{Funding}

This work was financially supported by the Swedish Research Council for Health, Working Life and Welfare and the Swedish Social Insurance Agency. The funders had no role in the study design, obtaining data, analyses, interpretation of data nor in writing the manuscript. Open Access funding provided by Karolinska Institutet.

\section{Declarations}

Ethics approval and consent to participate

The project was approved by the Regional Ethical Review Board of Stockholm (2007/762-31, 2009/1937-32, 2011/806-32, 2011/1710-32), Sweden. The Regional Ethical Review Board of Stockholm is one of the six regional ethical boards under the governmental Swedish Ethical Review Board. The project was conducted in accordance with the Declaration of Helsinki.

\section{Consent for publication}

Not applicable.

\section{Competing interests}

The authors declare that they have no competing interests.

\section{Author details}

'Division of Insurance Medicine, Department of Clinical Neuroscience, Karolinska Institutet, SE-171 77 Stockholm, Sweden. ${ }^{2}$ Division of Biostatistics, Institute of Environmental Medicine, Karolinska Institutet, Stockholm, Sweden.

${ }^{3}$ Department of Political Sciences, University of Pisa, Pisa, Italy.

Received: 9 August 2019 Accepted: 24 March 2021

Published online: 09 April 2021

\section{References}

1. International Agency for Research on Cancer (IARC). GLOBOCAN 2012. Lyon. France: GLOBOCAN 2013 (IARC) Section of cancer information; 2013.

2. de Boer AGEM. The European Cancer and work network: CANWON. J Occup Rehabil. 2014;24(3):393-8. https://doi.org/10.1007/s10926-013-9474-5.

3. de Boer AG, Taskila T, Tamminga SJ, Frings-Dresen MH, Feuerstein M, Verbeek JH. Interventions to enhance return-to-work for cancer patients. Cochrane Database Syst Rev. 2011;16(2). https://doi.org/10.1002/14651858. CD007569.pub2.

4. Petersson LM, Wennman-Larsen A, Nilsson M, Olsson M, Alexanderson K. Work situation and sickness absence in the initial period after breast cancer surgery. Acta Oncol. 2011;50(2):282-8. https://doi.org/10.3109/0284186X.201 0.533191.

5. Roelen CA, Koopmans PC, de Graaf JH, Balak F, Groothoff JW. Sickness absence and return to work rates in women with breast cancer. Int Arch Occup Environ Health. 2009;82(4):543-6. https://doi.org/10.1007/s00420-0080359-4.

6. Cancer incidence in Sweden 2011. In Stockholm: The National Board of Health and Welfare; 2012. Available at: https://www.socialstyrelsen.se/globa lassets/sharepoint-dokument/artikelkatalog/statistik/2012-12-19.pdf.

7. Petersson LM, Nilsson MI, Alexanderson K, Olsson M, Wennman-Larsen A. How do women value work shortly after breast cancer surgery and are their valuations associated with being on sick leave? J Occup Rehabil. 2013 Sep; 23(3):391-9. https://doi.org/10.1007/s10926-012-9402-0.

8. Kennedy F, Haslam C, Munir F. Pryce J. Returning to work following cancer: a qualitative exploratory study into the experience of returning to work 
following cancer. Eur J Cancer Care. 2007;16(1):17-25. https://doi.org/1 0.1111/j.1365-2354.2007.00729.x.

9. Park J, Shubair M. Returning to work after breast cancer: a critical review. Int J Disabil Manag. 2013;8. https://doi.org/10.1017/idm.2012.7.

10. Peteet JR. Cancer and the meaning of work. Gen Hosp Psychiatry. 2000; 22(3):200-5. https://doi.org/10.1016/S0163-8343(00)00076-1.

11. Johnsson A, Fornander T, Rutqvist LE, Vaez M, Alexanderson K, Olsson M. Predictors of return to work ten months after primary breast cancer surgery. Acta Oncol. 2009;48(1):93-8. https://doi.org/10.1080/02841860802477899.

12. Bouknight RR, Bradley CJ, Luo ZH. Correlates of return to work for breast cancer survivors. J Clin Oncol. 2006;24(3):345-53. https://doi.org/10.1200/ JCO.2004.00.4929.

13. Kvillemo P, Mittendorfer-Rutz E, Bränström R, Nilsson $K$, Alexanderson K Sickness absence and disability pension after breast cancer diagnosis: a 5 year nationwide cohort study. J Clin Oncol. 2017;35(18):2044-52 JCO.2015. 2066.0613.

14. Lundh MH, Lampic C, Nordin K, Ahlgren J, Bergkvist L, Lambe M, et al. Sickness absence and disability pension following breast cancer - a population-based matched cohort study. Breast. 2014;23(6):844-51. https:// doi.org/10.1016/j.breast.2014.09.007.

15. Eaker S, Wigertz A, Lambert PC, Bergkvist L, Ahlgren J, Lambe M. Breast cancer, sickness absence, income and marital status. a study on life situation 1 year prior diagnosis compared to 3 and 5 years after diagnosis. PloS One. 2011;6(3):e18040.

16. Paalman $\mathrm{CH}$, van Leeuwen $\mathrm{FE}$, Aaronson NK, de Boer AG, van de Poll-Franse L, Oldenburg HS, et al. Employment and social benefits up to 10 years after breast cancer diagnosis: a population-based study. Br J Cancer. 2016;114(1): 81-7. https://doi.org/10.1038/bjc.2015.431.

17. Noeres D, Park-Simon TW, Grabow J, Sperlich S, Koch-Giesselmann H, Jaunzeme J, et al. Return to work after treatment for primary breast cancer over a 6-year period: results from a prospective study comparing patients with the general population. Support Care Cancer. 2013;21(7):1901-9. https://doi.org/10.1007/s00520-013-1739-1.

18. Petersson LM, Vaez M, Nilsson MI, Saboonchi F, Alexanderson K, Olsson M, et al. Sickness absence following breast cancer surgery: a two-year followup cohort study. Scand J Caring Sci. 2018;32(2):715-24. https://doi.org/1 $0.1111 /$ scs. 12502.

19. Johnsson A, Fornander T, Rutqvist LE, Olsson M. Work status and life changes in the first year after breast cancer diagnosis. Work (Reading, Mass). 2011:38(4):337-46.

20. Islam T, Dahlui M, Abd Majid H, Nahar AM, Taib NAM, Su TT. My BCCSG: factors associated with return to work of breast cancer survivors: a systematic review. BMC Public Health. 2014;14(Suppl 3):S8. https://doi.org/1 0.1186/1471-2458-14-S3-S8.

21. Fantoni SQ, Peugniez C, Duhamel A, Skrzypczak J, Frimat P, Leroyer A. Factors related to return to work by women with breast cancer in northern France. J Occup Rehabil. 2010;20(1):49-58. https://doi.org/10.1007/s10926009-9215-y.

22. Drolet M, Maunsell E, Mondor M, Brisson C, Brisson J, Masse B, et al. Work absence after breast cancer diagnosis: a population-based study. Can Med Assoc J. 2005;173(7):765-U718. https://doi.org/10.1503/cmaj.050178.

23. Mujahid MS, Janz NK, Hawley ST, Griggs JJ, Hamilton AS, Graff J, et al. Racial/ ethnic differences in job loss for women with breast cancer. J Cancer Surviv Res Pract. 2011;5(1):102-11. https://doi.org/10.1007/s11764-010-0152-8.

24. Ahn E, Cho J, Shin DW, Park BW, Ahn SH, Noh DY, et al. Impact of breast cancer diagnosis and treatment on work-related life and factors affecting them. Breast Cancer Res Treat. 2009;116(3):609-16. https://doi.org/10.1007/ s10549-008-0209-9.

25. Peuckmann V, Ekholm O, Sjogren P, Rasmussen NK, Christiansen P, Moller $\mathrm{S}$, et al. Health care utilisation and characteristics of long-term breast cancer survivors: nationwide survey in Denmark. Eur J Cancer. 2009;45(4):625-33. https://doi.org/10.1016/j.ejca.2008.09.027.

26. Balak F, Roelen CAM, Koopmans PC, ten Berge EE, Groothoff JW. Return to work after early-stage breast cancer: a cohort study into the effects of treatment and cancer-related symptoms. J Occup Rehabil. 2008;18(3):26772. https://doi.org/10.1007/s10926-008-9146-z.

27. Johnsson A, Fornander T, Olsson M, Nystedt M, Johansson H, Rutqvist LE. Factors associated with return to work after breast cancer treatment. Acta Oncol. 2007;46(1):90-6. https://doi.org/10.1080/02841860600857318.

28. Blinder VS, Patil S, Thind A, Diamant A, Hudis CA, Basch E, et al. Return to work in low-income Latina and non-Latina white breast cancer survivors: a 3-year longitudinal study. Cancer. 2012;118(6):1664-74. https://doi.org/10.1 002/cncr.26478.

29. Smedley B, Stith A, Nelson A. Confronting racial and ethnic disparities in health care. Washington, DC: The National Academies Press; 2003.

30. Meilleur A, Subramanian SV, Plascak JJ, Fisher JL, Paskett ED, Lamont EB, Rural residence and cancer outcomes in the United States: issues and challenges. Cancer Epidemiol Biomark Prev. 2013;22(10):1657-67. https://doi. org/10.1158/1055-9965.EPI-13-0404.

31. Roelen CA, Koopmans PC, van Rhenen W, Groothoff JW, van der Klink JJ, Bultmann U. Trends in return to work of breast cancer survivors. Breast Cancer Res Treat. 2011;128(1):237-42. https://doi.org/10.1007/s10549-010-1330-0.

32. Alexanderson K. Sickness absence: a review of performed studies with focused on levels of exposures and theories utilized. Scand J Soc Med. 1998;26(4):241-9. https://doi.org/10.1177/14034948980260040301.

33. Allebeck P, Mastekaasa A. Swedish Council on Technology Assessment in Health Care (SBU). Chapter 5. Causes of sickness absence: research approaches and explanatory models. Scand J Public Health. 2004; 32(Supplement 63):36-43.

34. Closing the Gender Gap: Act Now. In.: OECD; 2012. ISBN:9789264179370 (PDF), https://doi.org/10.1787/9789264179370-en.

35. Burgess C, Cornelius V, Love S, Graham J, Richards M, Ramirez A. Depression and anxiety in women with early breast cancer: five year observational cohort study. Bmj. 2005;330(7493):4.

36. Reich M, Lesur A, Perdrizet-Chevallier C. Depression, quality of life and breast cancer: a review of the literature. Breast Cancer Res Treat. 2008;110(1): 9-17. https://doi.org/10.1007/s10549-007-9706-5.

37. Pedersen J, Bjorner JB, Burr H, Christensen KB. Transitions between sickness absence, work, unemployment, and disability in Denmark 2004-2008. Scand J Work Environ Health. 2012;38(6):516-26.

38. Steyerberg E. Clinical prediction models. New York: Springer; 2009. https:// doi.org/10.1007/978-0-387-77244-8.

39. WHO: International statistical classification of diseases and related health problems, tenth revision (ICD-10). 2010.

40. WHO. Pathlogy and genetics of tumors of the breast and female genital organs. Lyon: IARC Press; 2003.

41. Ludvigsson JF, Otterblad-Olausson P, Pettersson BU, Ekbom A. The Swedish personal identity number: possibilities and pitfalls in healthcare and medical research. Eur J Epidemiol. 2009;24(11):659-67. https://doi.org/10.1007/s1 0654-009-9350-y.

42. Social insurance in figures 2015. The Swedish Social Insurance Agency; 2015. ISSN: 2000-1703. Available at: https:/www.forsakringskassan.se/wps/ wcm/connect/e37b4ff1-d5d2-42dc-896b-bac5c59390e6/socialforsakringen_ i_siffror_2015_engelsk.pdf?MOD=AJPERES.

43. Ljungdahl LO, Bjurulf $\mathrm{P}$. The accordance of diagnoses in a computerized sick-leave register with doctor's certificates and medical records. Scand J Soc Med. 1991;19(3):148-53. https://doi.org/10.1177/140349489101900302.

44. Saboonchi F, Petersson LM, Wennman-Larsen A, Alexanderson K, Brannstrom R, Vaez M. Changes in caseness of anxiety and depression in breast cancer patients during the first year following surgery: patterns of transiency and severity of the distress response. Eur J Oncol Nurs. 2014; 18(6):598-604. https://doi.org/10.1016/j.ejon.2014.06.007.

45. Saboonchi F, Petersson LM, Wennman-Larsen A, Alexanderson K, Vaez M. Trajectories of anxiety among women with breast Cancer: a proxy for adjustment from acute to transitional survivorship. J Psychosoc Oncol. 2015; 33(6):603-19. https://doi.org/10.1080/07347332.2015.1082165.

46. Agresti A. Categorical data analysis. New York: Wiley-Interscience; 2002. https://doi.org/10.1002/0471249688.

47. Hosmer JDW, Lemeshow S, Sturdivant RX. Applied logistic regression, 3 edn: John Wiley \& Sons, Inc; 2013. https://doi.org/10.1002/9781118548387.

48. Hastie T. Generalized additive models. In: Chambers J, Hastie T, editors. Statistical Models in S: Wadsworth \& Brooks/Cole; 1992.

49. De Boer C. A practical guide to splines: springer; 2001.

50. Olsson D, Alexanderson K, Bottai M. Sickness absence and the time-varying excess risk of premature death: a Swedish population-based prospective cohort study. J Epidemiol Community Health. 2015;69(11):1052-7. https:// doi.org/10.1136/jech-2015-205886.

51. Hastie T, Tibshirani R, Friedman JH. The elements of statistical learning: data mining, inference, and prediction. 2nd ed; 2009. https://doi.org/10.1007/9780-387-84858-7.

52. Fawcett T. An introduction to ROC analysis. Pattern Recogn Lett. 2006;27(8): 861-74. https://doi.org/10.1016/j.patrec.2005.10.010. 
53. Ludvigsson JF, Andersson E, Ekbom A, Feychting M, Kim J-L, Reuterwall C, et al. External review and validation of the Swedish national inpatient register. BMC Public Health. 2011;11(1):450. https://doi.org/10.1186/1471-24 58-11-450.

54. Ludvigsson JF, Almqvist C, Bonamy AK, Ljung R, Michaelsson K, Neovius M, et al. Registers of the Swedish total population and their use in medical research. Eur J Epidemiol. 2016;31(2):125-36. https://doi.org/10.1007/s10654016-0117-y.

55. Borg K, Goine H, Söderberg E, Marnetoft SU, Alexanderson K. Comparison of seven measures of sickness absence based on data from three counties in Sweden. Work (Reading, Mass). 2006;26(4):421-8.

56. Hensing G. Swedish council on technology assessment in health care (SBU). Chapter 4. Methodological aspects in sickness-absence research. Scand J Public Health Suppl. 2004;63:44-8. https://doi.org/10.1080/14034 950410021844.

57. G H. The measurements of sickness absence - a theoretical perspective. Norsk Epidemiol. 2009;19(2):147-51.

58. Lauber C. Stigma and discrimination against people with mental illness: a critical appraisal. Epidemiol Psichiatr Soc. 2008;17(1):10-3. https://doi.org/1 0.1017/S1121189X0000261X.

59. Rahman S, Mittendorfer-Rutz E, Alexanderson K, Jokinen J, Tinghog P. Disability pension due to common mental disorders and healthcare use before and after policy changes; a nationwide study. Eur J Pub Health. 2017; 27(1):90-6. https://doi.org/10.1093/eurpub/ckw211.

60. Lidwall U. Termination of sickness benefits or transition to disability pension after changes in sickness insurance: a Swedish register study. Disabil Rehabil. 2013;35(2):118-24. https://doi.org/10.3109/09638288.2012.689920.

61. Fann JR, Thomas-Rich AM, Katon WJ, Cowley D, Pepping M, McGregor BA, et al. Major depression after breast cancer: a review of epidemiology and treatment. Gen Hosp Psychiatry. 2008;30(2):112-26. https://doi.org/10.1016/j. genhosppsych.2007.10.008.

62. Leijon O, Josephson M, Österlund N. How common is change of primary diagnosis during an episode of sickness benefit? A register study of medical sickness certificates issued 2010-2012 in Sweden. Scand J Soc Med. 2014; 43(1):44-51.

63. Roelen C, Thorsen S, Heymans M, Twisk J, Bültmann U, Bjørner J. Development and validation of a prediction model for long-term sickness absence based on occupational health survey variables. Disabil Rehabil. 2018:40(2):168-75. https://doi.org/10.1080/09638288.2016.1247471.

\section{Publisher's Note}

Springer Nature remains neutral with regard to jurisdictional claims in published maps and institutional affiliations.

Ready to submit your research? Choose BMC and benefit from:

- fast, convenient online submission

- thorough peer review by experienced researchers in your field

- rapid publication on acceptance

- support for research data, including large and complex data types

- gold Open Access which fosters wider collaboration and increased citations

- maximum visibility for your research: over $100 \mathrm{M}$ website views per year

At $\mathrm{BMC}$, research is always in progress.

Learn more biomedcentral.com/submissions 